\title{
Letting Go of Mandatory Presence during Laboratory Classes: Student's Behaviour and Opinions
}

\author{
Moniek A. M. Munneke',2, Florieke Eggermont ${ }^{2}$, Maarten C. de Waal Malefijt ${ }^{3}$, \\ Marc A. T. M. Vorstenbosch' ${ }^{1}$ Jan G. M. Kooloos ${ }^{1}$, Esther Tanck ${ }^{2 *}$ \\ ${ }^{1}$ Department of Anatomy, Radboud University Medical Center, Nijmegen, The Netherlands \\ ${ }^{2}$ Orthopaedic Research Lab, Radboud University Medical Center, Radboud Institute for Health Sciences, Nijmegen, The Netherlands \\ ${ }^{3}$ Department of Orthopaedics, Radboud University Medical Center, Radboud Institute for Health Sciences, Nijmegen, The Netherlands \\ Email: *Esther.tanck@radboudumc.nl
}

How to cite this paper: Munneke, M. A. M., Eggermont, F., de Waal Malefijt, M. C., Vorstenbosch, M. A. T. M., Kooloos, J. G. M., \& Tanck, E. (2019). Letting Go of Mandatory Presence during Laboratory Classes: Student's Behaviour and Opinions. Creative Education, 10, 2367-2373. https://doi.org/10.4236/ce.2019.1011168

Received: September 19, 2019 Accepted: November 4, 2019

Published: November 7, 2019

Copyright $\odot 2019$ by author(s) and Scientific Research Publishing Inc. This work is licensed under the Creative Commons Attribution International License (CC BY 4.0).

http://creativecommons.org/licenses/by/4.0/

\section{(c) (i) Open Access}

\begin{abstract}
To prepare the faculty of the Medical School of the Radboud university medical center in Nijmegen for the new curriculum based on components of self-directed learning that started in 2015, the behaviour in registration, presence and educational experiences of old curriculum students towards one of the components of self-directed learning: the letting go of mandatory classes was studied in 2014. Freedom to attend was introduced in human anatomy laboratories during a Year- 1 and a Year- 2 course. A web-based enrolment system was used, and student's choices and changes were logged. Student's opinions on the optional classes were probed with a questionnaire. Year-2 students liked the optional classes more than Year-1 students. Both groups disliked classes that were scheduled at the end of the day. Both groups perceived that the freedom to attend stimulated their responsibility and learning experience. In conclusion, the freedom to attend classes caused perceptions that are congruent with self-directed learning. The findings suggest that feelings of autonomy and being competent to the required task were stimulated by the freedom of choice. Implementing the freedom to attend classes in medical education is therefore recommended whereas one should also consider the feasibility with respect to organisation, efficient use of teachers and financial resources.
\end{abstract}

\section{Keywords}

Human Anatomy Laboratories, Mandatory Classes, Self-Directed Learning

\section{Introduction}

Self-directed learning is an educational theory in which students are enabled to 
learn on their own initiative, i.e. to choose what and how they learn (Garrison, 1997; Knowles, 1975; Slater \& Cusick, 2017). Knowles defines self-directed learning as "a process in which individuals take the initiative, with or without the help of others, in diagnosing their learning needs, formulating learning goals, identifying human and material resources for learning, choosing and implementing appropriate learning strategies, and evaluating learning outcomes" (Knowles, 1975: p. 18). One of the key items of self-directed learning is that students can choose their own learning path (Garrison, 1997; Knowles, 1975). It is thought that students can focus on subjects they know very little about and enhance retention of information (Gureckis \& Markant, 2012). Since self-directed learning has shown to be associated with lifelong learning (Murad \& Varkey, 2008) and therefore can be useful for students and doctors that need to acquire the biomedical knowledge that keeps on growing, this theory is being implemented in medical education over the past years (Premkumar et al., 2018), also at the Radboud university medical center (Radboudumc) in Nijmegen.

In 2014, the curricula Biomedical Sciences and Medicine of the Radboudumc were in transition from a curriculum based on problem-oriented learning and control of student's presence during laboratory work, towards a new curriculum embracing components of self-directed learning, offering amongst others non-obligatory educational activities. The hitherto applied registration of student's attendance in laboratory classes seems to have been driven by other issues than educational ones, since almost all literature shows that mandatory classes should be abolished.

Non-obligatory classes are associated with the promotion of student engagement in terms of autonomy, self-control and intrinsic motivation (Van de Vleuten \& Driessen, 2014), and although learning activities in medical schools should be stimulated, making participation mandatory to achieve this seems to be undesirable and may lead to physical presence without much engagement (St. Claire, 1999; Stegers-Jager et al., 2012). Ackerman et al. (2014) reported that students respond positively to having a limited number of choices-as opposed to an abundance of choices or having no choice at all.

The goal of this study was to analyse the behaviour in registration, presence and educational experiences of old curriculum students towards one of the components of self-directed learning: the letting go of mandatory classes. To prepare the faculty for the expected but unpredictable changing behaviour of students in the self-directed learning curriculum to come, we offered students who were used to mandatory laboratory classes voluntary classes. We expected that these students, already adapted to the control of presence, would behave and react differently than students who just entered medical school. Also because age, year level and previous education are thought to have an influence on the readiness of self-directed learning (Slater \& Cusick, 2017). Therefore this study was carried out in Year-1 students after one month and in Year-2 students after one-and-a-half year at the Radboudumc. We hypothesize that Year-2 stu- 
dents experience the letting go of some mandatory laboratory classes as a relief and report positively, whereas the reaction of the Year-1 students, being tabulae rasae towards voluntary classes, is more neutral compared to Year-2 students.

\section{Methods}

We conducted this study in 2014 at the medical faculty of the Radboudumc, Nijmegen, The Netherlands. In October, Year-1 students of Biomedical Sciences and Medicine followed a 4-week course dedicated to human anatomy with six anatomy laboratory sessions, three of which were made optional. In April, Year-2 students followed a 4-week course on the musculoskeletal system with three anatomy laboratory sessions, two of which were made optional.

For the optional laboratory sessions, all students received access to an online enrolment system. In this enrolment system, the students could see the available places, register and, if needed, change their entry up to an hour before the start of the laboratory session. All the selections of the students were registered, but only the data from the students who gave informed consent at the end of the module was used for analysis.

To analyse the behaviour in presence and educational experiences of the students, we used an evaluation form that was acquired together with an education specialist. At the end of the module, all students were asked to fill out the paper-based evaluation form on their experience with self-planning of the laboratory sessions. The evaluation form was distributed one day before the end of the course. The form included the informed consent, a questionnaire on the attendance to the laboratory sessions (what sessions did you attend and why, at what time slot and why), and 12 six-option-Likert-style items with prepositions about components of self-directed learning (e.g. (Ryan \& Deci, 2000)) such as motivation, feelings of autonomy and perceived participation (Table 2). The actual attendance was not checked at the door of the anatomy laboratory sessions, so could only be based on the self-reported attendance in the questionnaire.

Descriptive analyses were performed on the questionnaire data. Pearson $\chi^{2}$ tests were performed to test the differences between the Year-1 and Year-2 students. For the analyses, a $p$-value $<0.004$ (Bonferroni corrected; 0.05/12) was considered significant.

According to the Dutch law on experiments with humans, this study was exempt from the formal ethical review process. Written consent of all subjects was obtained. The ethical principles of the Declaration of Helsinki were taken into account during the study design, data collection and data analysis phases. Informed consent was taken as first part of the questionnaire.

\section{Results}

In total, 487 and 368 students registered in the Year-1 and Year-2 course, respectively. Of the registered students, 405 Year-1 and 275 Year- 2 students gave informed consent to use their data from the enrolment tool and questionnaire 
for analysis. Table 1 shows the number of students and characteristics of class participation of both included cohorts. About $85 \%$ of the included students enrolled and attended the laboratory sessions. In some cases there was a mismatch in the data from the system and the reported attendance in the questionnaire. About $5 \%$ of the students did enrol but did not attend the sessions, whereas about 5\% did attend the classes without enrolling, and $6 \%$ did not enrol nor attend the classes (Table 1).

The enrolment tool not only gave the students the opportunity to book a time slot, but also gave them the opportunity to switch to another time slot. Sixty percent of the students simply booked a slot and attended without changes. Most others changed a few times whereas a few students even changed nine times.

Most of the students preferred to go to the optional laboratory sessions at the time slots between 09:30 and 15:00 hours. Least preferred were the time slots at the end of the day (after 15:00 hours). However, the free commentaries on the questionnaire revealed that a few students deliberately chose time slots at the end of the day because they were aware of the unpopularity of these slots thereby expecting to receive more attention from the assisting faculty at these slots.

The reasons that were mentioned in the questionnaire to not attend the laboratory sessions did not differ much between Year-1 and Year-2 students and can be summarized as: "session did not fit my own schedule", "the ideal time slots were booked and I did not want to attend another slot" and "I had other/more important things to do". The Year-2 students gave an additional argument: "I preferred to study the anatomy outside the dissection room".

Comparison Year 1 and Year 2 students

Table 2 presents the six-option-Likert-style items as used in the questionnaire and the mean score on each item for the Year-1 and Year-2 students. The Pearson $\chi^{2}$ tests showed several significant differences between the student groups. The Year-2 students 1) were more content that they could schedule the laboratory session themselves; 2) perceived their fellow students were better able to

Table 1. Student numbers and characteristics.

\begin{tabular}{lcc}
\hline & Year 1 & Year 2 \\
\hline $\begin{array}{l}\text { Number of students registered in 4-wks module } \\
\begin{array}{l}\text { Number of students, data available (questionnaire and } \\
\text { enrolment system data) }\end{array}\end{array}$ & 487 (83\%) & $275(75 \%)$ \\
$\begin{array}{l}\text { Gender (female vs. male) } \\
\text { Number of students that enrolled (system) and attended }\end{array}$ & $65 \%$ vs. 35\% & $68 \%$ vs. 32\% \\
(self-reported) optional laboratory sessions & $340(84 \%)$ & $238(86 \%)$ \\
$\begin{array}{l}\text { Number of students that enrolled (system) but did not attend } \\
\text { (self-reported) optional laboratory sessions }\end{array}$ & $23(6 \%)$ & $8(3 \%)$ \\
$\begin{array}{l}\text { Number of students that did not enroll (system) but attended } \\
\text { (self-reported) optional laboratory sessions }\end{array}$ & $18(4 \%)$ & $13(5 \%)$ \\
$\begin{array}{l}\text { Number of students that did not enroll (system) nor attended } \\
\text { (self-reported) optional laboratory sessions }\end{array}$ & $24(6 \%)$ & $16(6 \%)$ \\
\hline
\end{tabular}


Table 2. Prepositions in questionnaire.

\begin{tabular}{|c|c|c|c|}
\hline Prepositions & Year 1 & Year 2 & $p$ value \\
\hline $\begin{array}{l}\text { It was very nice that I was given the choice to register myself for the } \\
\text { laboratory sessions }\end{array}$ & $2.3(1.1)$ & $1.8(1.0)$ & $<0.001^{\star}$ \\
\hline Given the choice, I felt more connected to the content of the course & $3.5(1.4)$ & $3.4(1.4)$ & 0.144 \\
\hline $\begin{array}{l}\text { Given the choice, I felt more conscious about my future career as a } \\
\text { doctor and/or investigator }\end{array}$ & $3.3(1.3)$ & $3.4(1.4)$ & 0.173 \\
\hline Given the choice, I felt more conscious about my own responsibility & $2.3(1.1)$ & $2.1(1.0)$ & 0.573 \\
\hline Given the choice, I felt more conscious about the content of the course & $3.3(1.3)$ & $3.0(1.3)$ & 0.067 \\
\hline $\begin{array}{l}\text { Given the choice, I felt I was better able to handle the content of the } \\
\text { course }\end{array}$ & $3.7(1.3)$ & $3.6(1.3)$ & 0.545 \\
\hline $\begin{array}{l}\text { Given the choice, I perceived that my fellow students are better able } \\
\text { to handle the content of the course }\end{array}$ & $3.9(1.2)$ & $3.7(1.3)$ & $0.001^{*}$ \\
\hline Given the choice, I prepared myself better for the content of the course & $3.6(1.3)$ & $3.0(1.3)$ & $<0.001^{\star}$ \\
\hline Given the choice, I learned more during the laboratory sessions & $3.6(1.3)$ & $3.2(1.3)$ & 0.006 \\
\hline Given the choice, I felt more stimulated to perform the best I can & $3.4(1.3)$ & $2.8(1.2)$ & $<0.001^{\star}$ \\
\hline Given the choice, my fellow students were better prepared & $3.8(1.2)$ & $3.3(1.2)$ & $<0.001^{\star}$ \\
\hline Given the choice, my fellow students were working harder & $3.7(1.2)$ & $3.3(1.2)$ & $0.001^{*}$ \\
\hline Grade for optional sessions (scale $1-10$ ) & $7.4(1.1)$ & $7.7(1.5)$ & $<0.001^{\star}$ \\
\hline
\end{tabular}

handle the subject; 3) felt better prepared when entering the dissection room; 4) were more stimulated to do the best they can; 5) perceived their fellow student as better prepared, and 6) had more the feeling their fellow students worked harder in comparison to the Year-1 students. Overall, the students were content with the voluntary classes as can be concluded from the grades the students gave: 7.4 (out of ten) and 7.7 from Year-1 and Year-2 students, respectively.

\section{Discussion}

In this study we analysed the behaviour in registration, presence and educational experiences of students towards one of the components of self-directed learning: the letting go of mandatory classes. We showed that students, being familiar or not with mandatory university classes, like the freedom of choice to attend as well as the freedom of choice when to attend classes. They also perceived components that one wants to reach with this freedom, like experiencing more responsibility and stimulation to do their best. Our hypothesis was that the reaction of the Year-1 students, being tabulae rasae towards voluntary classes, would be more neutral compared to Year-2 students. The fact that students in Year-2 perceived more benefits than Year-1 students underpins the idea that letting go of mandatory classes stimulates self-directedness. These results are in agreement with the literature that suggests that freedom to attend is an essential condition in a self-directed curriculum (Van de Vleuten \& Driessen, 2014; St. Claire, 1999). 
The course in this study involved rather popular human anatomy laboratory sessions which stimulate high voluntary attendance, as shown by the presence of $85 \%$ of the students. The possibility for students to change their subscription up to one hour before the session had therefore little consequences for the use of facilities and deployment of the teaching staff. In other less popular classes voluntary attendance might be lower which would be inefficient for the use of facilities and available teachers. Indeed, in the new curriculum of 2015 we experienced that generally only between $50 \%-80 \%$ of the students show up at scheduled learning activities. This percentage was mainly dependent on the student's estimation of the usefulness of the learning activity to pass an upcoming summative test and on the timing of the learning activity related to the date of examination. Hence, to be able to anticipate, in the first year of the new curriculum a 5-day limit for subscribing or cancellations was introduced, which was later set to a 2-day limit, which worked better for both student and the teaching staff.

The students in this study were content with the freedom of subscribing for a limited number of educational sessions. In the introduced curriculum, the students had to subscribe for all educational activities. This stimulated the self-directed learning, but the downside was the sufficient amount of time it took the students to schedule their own program. Therefore, starting from September 2019, all students will be subscribed to the educational sessions but are for most learning activities free to participate or not.

Nevertheless, since class attendance is a better predictor of grades than study skills for instance (Credé et al., 2010), we are continuously searching for the best possible didactical and contextual motivators for our students to show up in the new curriculum. On the other hand, the need for efficient use of teaching and financial resources has demanded that non-mandatory attendance is partly being reversed already. This is especially true for activities that inherently require a minimal attendance, such as encounters with patients and for small group work activities.

In conclusion, the freedom to attend classes caused perceptions that are congruent with self-directed learning. The findings suggest that feelings of autonomy and being competent to the required task were stimulated by the freedom of choice. Implementing the freedom to attend classes in medical education is therefore recommended whereas one should also consider the feasibility with respect to organisation, efficient use of teachers and financial resources.

\section{Acknowledgements}

We would like to thank C.M.J. Spronk for the development of the online enrolment tool and Dr. C.R.M.G. Fluit for her critical view to the study design of the study.

\section{Conflicts of Interest}

The authors declare no conflicts of interest regarding the publication of this paper. 


\section{References}

Ackerman, D. S., Gross, B. L., \& Celly, K. S. (2014). Having Many Choice Options Seems like a Great Idea, But ...: Student Perceptions about the Level of Choice for a Project Topic in a Marketing Course. Journal of Marketing Research, 36, 221-232. https://doi.org/10.1177/0273475314522038

Credé, M., Roch, S. G., \& Kieszczynka, U. M. (2010). Class Attendance in College: A Meta-Analytic Review of the Relationship of Class Attendance with Grades and Student Characteristics. Review of Educational Research, 80, 272-295. https://doi.org/10.3102/0034654310362998

Garrison, D. R. (1997). Self-Directed Learning: Toward a Comprehensive Model. Adult Education Quarterly, 48, 18-33. https://doi.org/10.1177/074171369704800103

Gureckis, T. M., \& Markant, D. B. (2012). Self-Directed Learning: A Cognitive and Computational Perspective. Perspectives on Psychological Science, 7, 464-481. https://doi.org/10.1177/1745691612454304

Knowles, M. S. (1975). Self-Directed Learning: A Guide for Learners and Teachers. New York: Association Press.

Murad, M. H., \& Varkey, P. (2008). Self-Directed Learning in Health Professions Education. Annals Academy of Medicine Singapore, 37, 580-590.

Premkumar, K., Vinod, E., Sathishkumar, S., Pulimood, A. B., Umaefulam, V., Prasanna Samuel, P., \& John, T. A. (2018). Self-Directed Learning Readiness of Indian Medical Students: A Mixed Method Study. BMC Medical Education, 18, 134. https://doi.org/10.1186/s12909-018-1244-9

Ryan, R. M., \& Deci, E. L. (2000). Intrinsic and Extrinsic Motivations: Classic Definitions and New Directions. Contempory Educational Psychology, 25, 54-67.

https://doi.org/10.1006/ceps.1999.1020

Slater, C. E., \& Cusick, A. (2017). Factors Related to Self-Directed Learning Readiness of Students in Health Professional Programs: A Scoping Review. Nurse Education Today, 52, 28-33. https://doi.org/10.1016/j.nedt.2017.02.011

St. Claire, K. L. (1999). A Case against Compulsory Class Attendance Policies in Higher Education. Innovative Higher Education, 23, 171-180.

https://doi.org/10.1023/A:1022942400812

Stegers-Jager, K. M., Cohen-Schotanus, J., \& Themmen, A. P. N. (2012). Motivation, Learning Strategies, Participation and Medical School Performance. Medical Education, 46, 678-688. https://doi.org/10.1111/j.1365-2923.2012.04284.x

Van de Vleuten, C. P. M., \& Driessen, E. W. (2014). What Would Happen to Education If We Take Education Evidence Seriously? Perspectives on Medical Education, 3, 222-232. https://doi.org/10.1007/s40037-014-0129-9 